\title{
RANCANG BANGUN MESIN PEMARUT KELAPA SKALA RUMAH TANGGA BERUKURAN 1 KG PER WAKTU PARUT 9 MENIT DENGAN MENGGUNAKAN MOTOR LISTRIK 100 WATT
}

\author{
Joko Hardono \\ Jurusan Teknik Mesin - Universitas Muhammadiyah Tangerang
}

\begin{abstract}
ABSTRAK
Mesin parut kelapa adalah salah satu produk mesin dari hasil teknologi yang berfungsi sebagai alat untuk menghancurkan daging buah kelapa menjadi butiran-butiran kecil dengan tujuan untuk memperoleh santan yang terkandung di daging buah kelapa. Mesin parut kelapa yang sudah ada sekarang adalah mesin parut yang menggunakan motor bensin sebagai penggerak utamanya, dan bentuknya besar sehingga butuh tenaga untuk memindahkannya. Dari macam-macam ukuran mesin parut kelapa yang ada sekarang ini, sehingga pada penelitian ini mencoba memberikan ide untuk membuat mesin parut yang lebih sederhana dalam skala rumah tangga.

Proses perancangan mesin parut dilakukan dengan tahapan yaitu analisa kebutuhan, perencanaan, pembuatan, pengujian dan kesimpulan. Tenaga penggerak mesin parut menggunakan motor listrik, yang disesuaikan dengan kemampuan daya listrik masyarakat.

Hasil perancangan mesin menghasilkan mesin parut kelapa dengan spesifikasi panjang: 365 $\mathrm{mm}$, lebar: $150 \mathrm{~mm}$, tinggi: $200 \mathrm{~mm}$. Penggerak mesin menggunakan motor listrik dengan daya 100 watt, 220 volt. Transmisi menggunakan sabuk dan puli, masing-masing puli berdiameter $15 \mathrm{~mm}$ dan $45 \mathrm{~mm}$. Waktu yang diperlukan untuk memarut satu buah kelapa sekitar 4 menit 4 detik dan untuk memarut 1 kg kelapa diperlukan waktu $\pm 9,78$ menit.
\end{abstract}

\section{PENDAHULUAN}

Seiring dengan perkembangan zaman dan kemajuan teknologi yang sangat pesat banyak terciptanya produk-produk yang beredar di masyarakat, teknologi diciptakan untuk membantu meringankan pekerjaan masyarakat dan agar menghasilkan hasil yang lebih maksimal, salah satu contohnya yaitu mesin parut kelapa.

Mesin parut kelapa adalah salah satu produk mesin dengan hasil teknologi untuk kebutuhan rumah tangga yang berfungsi sebagai alat untuk menghancurkan daging buah kelapa menjadi butiran-butiran kecil, dengan tujuan untuk memperoleh santan yang terkandung di daging buah kelapa. Selama ini proses pemarutan kelapa yang dilakukan masyarakat dikerjakan dengan cara manual, yaitu dengan menggunakan parut kelapa yang terbuat dari plat besi yang mempunyai duriduri kecil yang terletak dipermukaan plat, cara ini sangat sederhana untuk memarut kelapa meskipun membutuhkan waktu untuk $1 \mathrm{~kg}$ kelapa, dan aman terhadap kecelakaan.

Untuk memenuhi kebutuhan santan yang banyak, masyarakat cenderung membeli kelapa yang sudah diparut oleh pedangang dipasar. Alat parut kelapa yang digunakan pedagang pasar menggunakan parut kelapa yang sudah dilengkapi dengan motor bensin, harga dari mesin parut kelapa ini sedikit mahal dan memerlukan perawatan.

Dari keadaan alat parut kelapa yang ada sekarang ini, menyebabkan masyarakat untuk lebih memilih membeli kelapa yang sudah diparut oleh pedagang dipasar dari pada memiliki mesin parut kelapa sendiri. Melihat dan meninjau masalah yang di hadapi masyarakat maka dibuat suatu peralatan yang lebih efisien untuk mempermudah dalam pengolahan daging buah kelapa. 
Pada rancang bangun mesin parut kelapa ini mengacu pada mesin parut kelapa motor bensin. Hanya saja, dimodifikasi pengerjaannya menjadi lebih sederhana dan menggunakan elektrik motor berukuran kecil. Maka rumusan masalahnya adalah sebagai berikut: Bagaimanakah langkah kerja dalam proses pembuatan mesin parut kelapa dan bagaimanakah hasil kerja dari proses pembuatan mesin parut kelapa.

Adapun tujuan rancang bangun mesin parut kelapa ini adalah untuk mewujudkan mesin parut kelapa yang mempunyai sistem sederhana, murah, mudah dioperasikan dan dirawat, serta dapat meningkatkan penggunaan mesin tersebut, dan untuk mendukung perkembangan teknologi mesin parut kelapa yang sudah ada di masyarakat dan industri kecil.

\section{TINJAUAN PUSTAKA}

Dalam tata nama atau sistematika (taksonomi) tumbuh-tumbuhan, tanaman kelapa (cocos nucifera) dimasukan kedalam klasifikasi sebagai berikut tumbuh-tumbuhan, tumbuh berbiji, biji tertutup dan biji berkeping satu.

Tanaman kelapa digolongkan ke dalam famili yang sama dengan sagu (metroxylon sp), salak (salaca edulis), aren (arenga pinata), dan lain-lain. Penggolongan varietes kelapa pada umumnya didasarkan pada perbedaan umur pohon mulai berubah bentuk dan ukuran buah, warna buah, serta sifat-sifat kusus yang lain.

Kelapa memiliki berbagai nama daerah. Secara umum, buah kelapa dikenal sebagai coconut, orang belanda menyebutnya kokosnoot atau klapper, sedangkan orang prancis menyebutnya cocotier. Di indonesia kelapa biasanya di sebut krambil atau klapa.

Mesin pemarut kelapa adalah suatu alat yang digunakan untuk membantu atau mempermudah pekerjaan manusia dalam hal pemarutan kelapa. Sumber tenaga utama mesin pemarut adalah tenaga motor, dimana tenaga motor digunakan untuk menggerakkan atau memutar mata parut melalui perantara sabuk ( $V$-belt). Mesin parut kelapa ini mempunyai sistem transmisi berupa puli. Gerak putar dari motor listrik ditransmisikan ke puli 1, kemudian dari puli 1 ditransmisikan ke puli 2 dengan menggunakan sabuk. Ketika motor dihidupkan, maka motor akan berputar kemudian putaran ditransmisikan oleh sabukuntuk menggerakan poros mata parut.

Dalam kehidupan sehari-hari kita sering menjumpai mesin pemarut kelapa, biasanya sering kita lihat di pasar-pasar. Mesin parut kelapa yang sudah ada antara lain:

1) Mesin parut dengan menggunakan motor bensin berkapasitas $2 \mathrm{PK}$

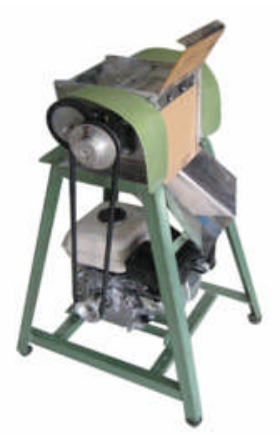

Gambar 2.1 Mesin parut kelapa motor bensin 2 PK 
2) Mesin parut dengan menggunakan motor listrik 0,5 HP.

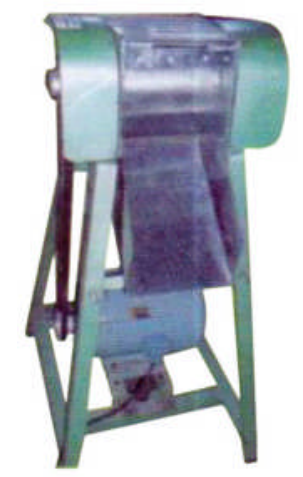

Gambar 2.3 Mesin parut kelapa motor listrik 125 Watt

Oleh karena itu dalam kesempatan ini perlu dibuat alat pemarut lain yang lebih efisien dan mudah digunakan, dimana konstruksi mesin lebih sederhana bila dibandingkan dengan mesin parut kelapa yang sebelumnya telah dibuat dan beredar di pasaran.

\section{Elemen Mesin}

Elemen mesin merupakan bagian penting dari bidang perancangan mekanis, perancangan menciptakan peralatan atau sistem untuk memenuhi kebutuhan-kebutuhan khusus. Peralatan mekanis biasanya meliputi komponen-komponen yang bergerak yang mengirimkan daya dan melakukan pola-pola gerak khusus.

Tentu saja elemen-elemen mesin tersebut harus sesuai, harus selaras, dan harus bekerja secara aman dan efisien, yang memenuhi kebutuhan konsumen. Perancang harus mempertimbangkan bukan hanya unjuk kerja elemen yang di rancang pada suatu waktu tertentu, tetapi juga memikirkan elemen-elemen yang akan di padukan.

\section{Poros dan Daya Poros}

Poros adalah komponen alat mekanisme yang mentransmisikan gerak berputar dan daya. Poros ini merupakan satu kesatuan dari sebaran sistem mekanis dimana daya ditransmisikan dari penggerak utama, misalnya motor listrik atau motor bakar, ke bagian lain yang berputar dari sistem. Ada beberapa macam sistem mekanisme yang berkaitan dengan elemen berputar yang mentrasmisikan daya.

Perhitungan gaya-gaya yang terjadi pada poros dalam proses pemindahan daya:

a). Daya rencana $(\mathrm{kW})$

$\mathrm{P} d=f_{\mathrm{c}} \times \mathrm{P}(\mathrm{kW})$

Keterangan:

$P_{d}=$ Daya yang direncanakan $(k W)$

$f_{\mathrm{c}}=$ Faktor koreksi

$\mathrm{P}$ = Daya yang ditransmisikan

Tabel 1. faktor koreksi daya yang ditransmisikan, $\mathrm{f}_{\mathrm{c}}$ 


\begin{tabular}{|l|c|}
\hline \multicolumn{1}{|c|}{ Daya yang akan ditransmisikan } & $f_{c}$ \\
\hline Daya rata-rata yang diperlukan & $1,2-2,0$ \\
\hline Daya maksimum yang diperlukan & $0,8-1,2$ \\
\hline Daya normal & $1,2-1,0$ \\
\hline
\end{tabular}

b). Daya poros / daya yang diperlukan (p)

$$
P=\frac{2 . \pi \cdot N \cdot T}{60}
$$

$\mathrm{P}=$ Daya poros dari poros penggerak pisau (kW)

$\mathrm{T}=$ Torsi $(\mathrm{Nm})$

$\mathrm{N}=$ Putaran (RPM)

c). Torsi (T)

$\mathrm{T}=\mathrm{Fxd}(\mathrm{Nm})$

$\mathrm{F}=$ Gaya Sentrifugal dari benda berputar / Gaya beban daging kelapa ke mata pisau (N)

$\mathrm{d}=$ jarak benda ke pusat rotasi $(\mathrm{m})$

\section{METODOLOGI PENELITIAN}

\subsection{Diagram Alir Perancangan}

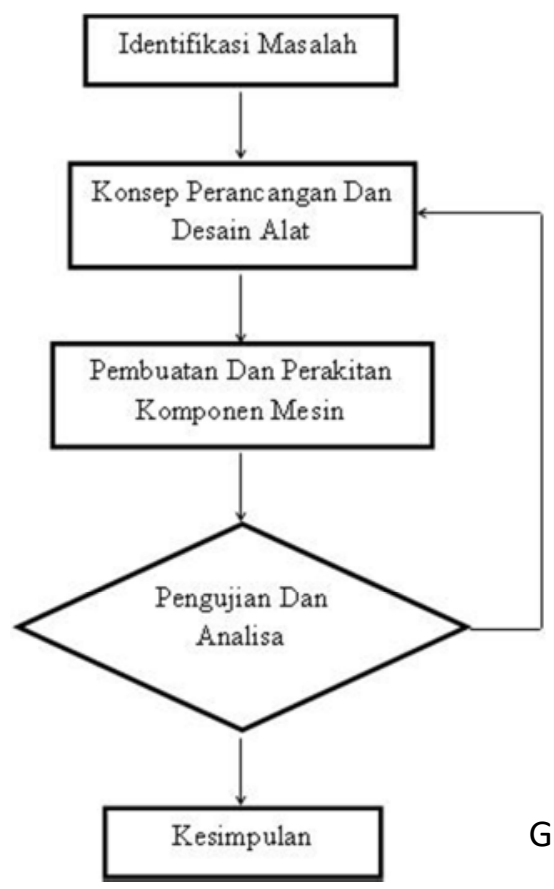

Gambar 3.1. Diagram alir

\subsection{Bagian-Bagian Mesin}


Adapun bagian-bagian utama mesin adalah:

1) Motor Listrik

Motor listrik merupakan sumber tenaga penggerak awal dari perancangan mesin ini. Motor listrik bekerja untuk memutar atau menggerakan mata parut melaui perantara sabuk (V-belt).

2) Hopper (corong)

Hopper adalah bagian yang digunakan untuk memasukkan bahan yang akan di parut dan sekaligus sebagai wadah parutan. Bagian ini langsung berhubungan dengan alat parut.

3) Mata parut

Mata parut ini terbuat dari pipa besi, dimana di bagian permukaan sekeliling pipa diukir menjadi seperti paku-paku kecil yang sedemikian rupa sehingga dapat memarut bahan karena gesekan.

4) Corong parut (Tempat keluar hasil parut)

Bagian ini merupakan tempat keluarnya hasil pemarutan, dimana bagian ini diharapkan mampu dengan mudah menurunkan hasil parutan.

5) Rangka mesin

Rangka mesin merupakan bagian yang berfungsi untuk menopang seluruh komponenkomponen utama dari mesin pemarut.

\subsection{Proses Pemarutan Kelapa}

Cara atau langkah-langkah dalam pemarutan kelapaadalah sebagai berikut:

1) Siapkan mesin pemarut kelapa

2) Siapkan bahan (daging buah kelapa)

3) Hidupkan motor

4) Masukan daging buah kelapa kedalam hopper mesin parut

5) Daging buah kelapa akan terparut oleh mata pisau parut

6) Hasil parutan akan keluar dari saluran tempat keluar mesin

7) Matikan mesin

\subsection{Bahan-Bahan}

1). Kerangka dan casing (penutup)

Kerangka yang merupakan casing, berfungsi sebagai penopang semua komponen elemen-elemen mesin, pada mesin ini kerangka menggunakan papan kayu dengan tebal $15 \mathrm{~mm}$. Dibentuk menjadi bagian-bagian seperti gambar berikut:

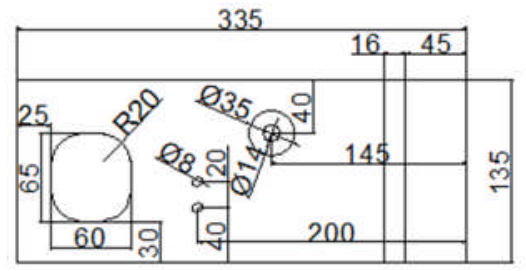

Gambar 3.2 desain casing kanan

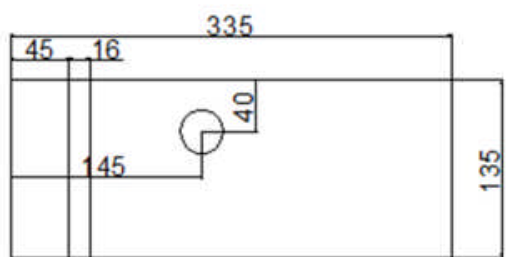

Gambar 3.3 desain casing kiri

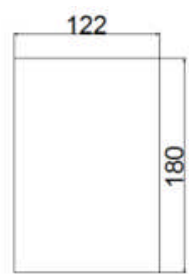

Gambar 3.8 desain casing bawah

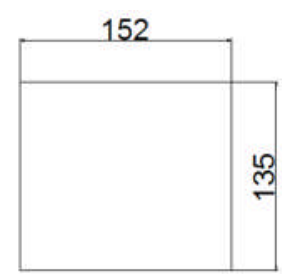

Gambar 3.4 desain casing depan

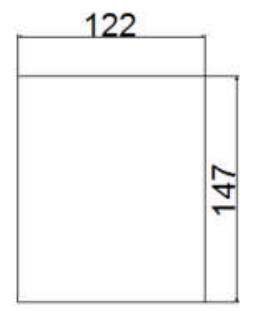

Gambar 3.5 desain casing tengah

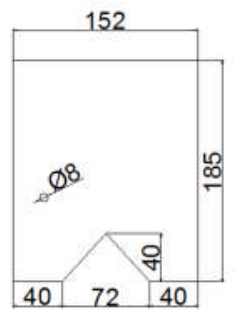

Gambar 3.6 desain casing belakang

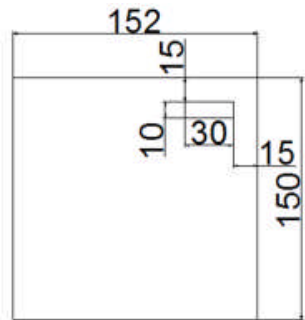

Gambar 3.7 desain casing atas 
2). Motor penggerak

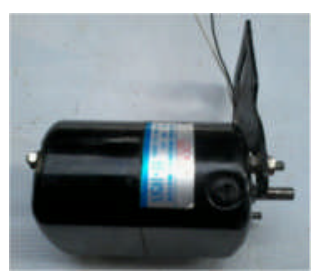

Gambar 3.9 motor

penggerak

Motor yang digunakan pada mesin parut kelapa ini mempunyai spesifikasi sebagai berikut:

$\begin{array}{ll}\text { Merk } & : \text { Sewing Machine Motor } \\ \text { Model } & : \text { HF-1026 N } \\ \text { Watt } & : 100 \text { watt } \\ \text { Volt } & : 220 \text { Volt } \\ \text { Putaran } & : 6000 \mathrm{Rpm}\end{array}$

3). Sabuk dan puli

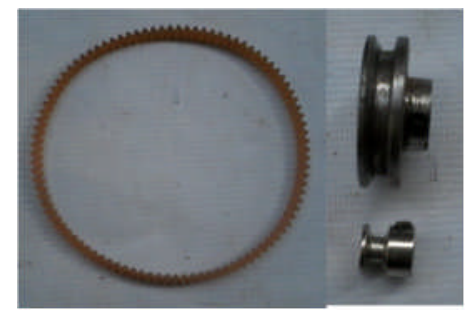

Gambar 3.10 sabuk dan puli

Masing-masing diameter puli adalah $15 \mathrm{~mm}$ untuk puli motor penggerak dan $45 \mathrm{~mm}$ untuk puli poros pisau mata parut. Panjang keliling sabuk $346 \mathrm{~mm}$.

4). Mata pisau parut

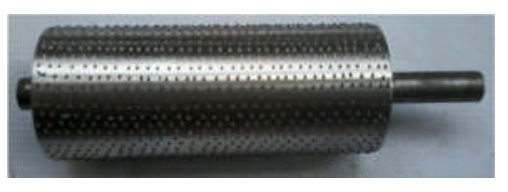

Gambar 3.11 pisau mata parut

Mata pisau parut merupakan komponen utama yang sangat penting, yang berfungsi sebagai alat untuk penghancur daging buah kelapa. Berbentuk silinder dan memiliki duri-duri diseluruh permukaannya.

Mata pisau parut terbuat dari bahan pipa steinlis yang berdiameter $50 \mathrm{~mm}$ dan panjang120 mm. Dengan poros yang berdiameter $12 \mathrm{~mm}$, dan panjang $180 \mathrm{~mm}$. Bahan poros pada mesin parut ini menggunakan baja S $45 \mathrm{C}$ dengan kekuatan tarik 58 $\mathrm{kg} / \mathrm{mm} 2$. 
5). Komponen-komponen lainnya:

- 2 buah bantalan gelinding dengan nomor 6201

- Saklar (tombol ON/OFF)

- Kabel

- Baut dan mur

- Baut sekrup

- Handle

6). Perakitan mesin

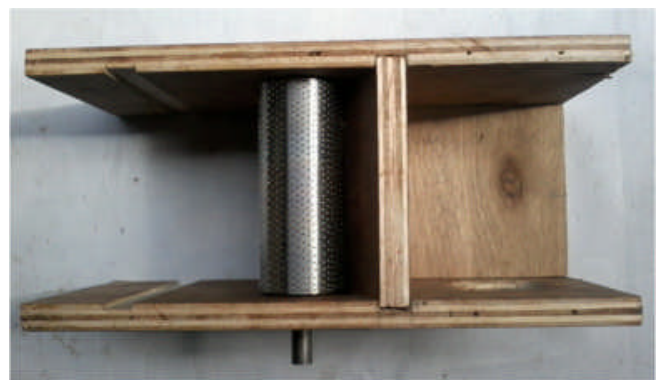

Gambar 3.12 perakitan kedua casing samping,mata pisau parut, casing tengahdan casing bawah

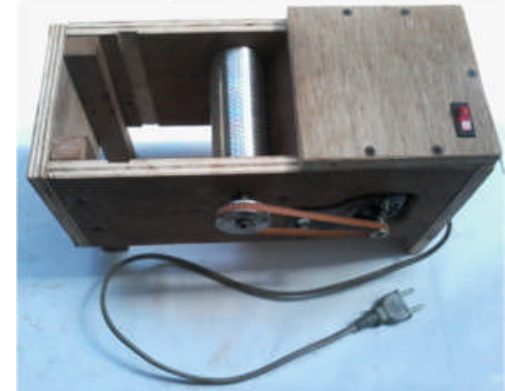

Gambar 3.14 perakitan kedua casing samping, casing tengah, kasing bawah, casing belakang, casing depan, kaki, motor penggerak, sabuk,

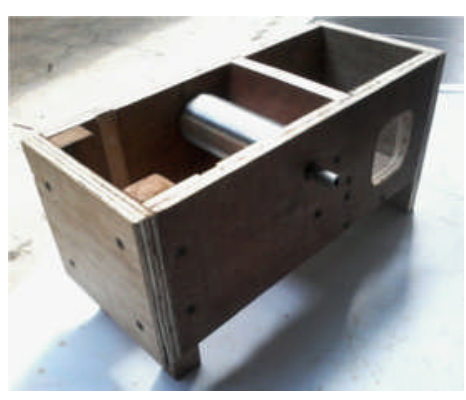

Gambar 3.13 perakitan kedua casing samping, casing tengah, casing tengah, casing bawah, casing

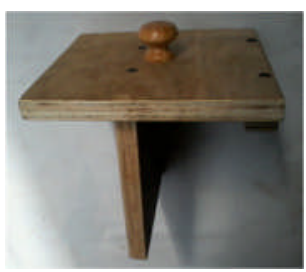

Gambar 3.15 Tutup mata parut

7). Hasil rangkaian mesin parut kelapa

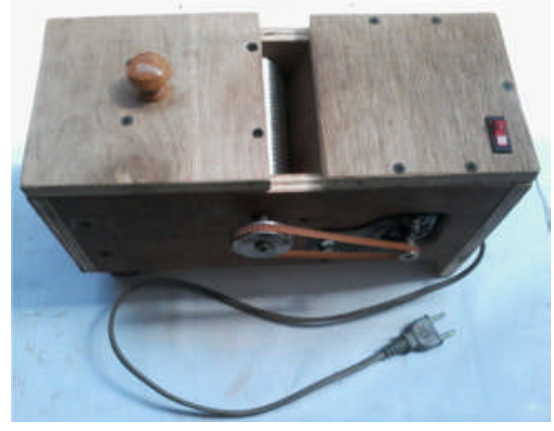

Gambar 3.16 mesin parut kelapa 


\section{PENGOLAHAN DATA DAN PEMBAHASAN}

\subsection{Pengujian mesin}

Setelah dilakukan proses perancangan dan proses pembuatan mesin parut kelapa maka langkah selanjutnya adalah melakukan uji kinerja mesin tersebut. Uji kinerja ini bertujuan untuk mengetahui kinerja mesin, sesuai atau tidak dengan konsep perancangan.

1). Bahan yang diperlukan untuk pengujian mesin:
a). Satu buah kelapa dengan diameter luar $130 \mathrm{~mm}$ dan teba $12 \mathrm{~mm}$ dibelah empat, dengan tujuan agar lebih mudah dimasukan kedalam mesin.
b). $1 \mathrm{~kg}$ kelapa
c). Stopwatch

2). Prosedur pengujian

Mesin dinyalakan, kelapa yang sudah di belah empat dimasukan kedalam mesin satu persatu, stopwatch dinyalakan semenjak potongan kelapa pertama dimasukan sampai dengan potongan kelapa terakhir habis terparut semua. Stopwatch digunakan untuk menghitung total waktu yang diperlukan mesin parut untuk memarut satu buah kelapa.

3). Hasil Pengujian

Berdasarkan hasil uji kinerja mesin dapat diambil kesimpulan bahwa:

a). untuk memarut satu buah kelapa yang berdiameter luar $130 \mathrm{~mm}$ dan tebal $12 \mathrm{~mm}$ diperlukan waktu selama 4 menit 4 detik.

b). Untuk memarut $1 \mathrm{~kg}$ kelapa diperlukan waktu selama 9,78 menit.

4.2 Perbandingan reduksi pada puli (i)

$i=\frac{n 1}{n 2}=\frac{D p}{d p} ; u=\frac{1}{i}$

$$
\begin{aligned}
& \text { Keterangan: } \\
& i \quad=\text { perbandingan reduksi pada puli } \\
& n_{1}=\text { putaran puli penggerak }(\mathrm{rpm}) \\
& n_{2}=\text { putaran puli yang di gerakan }(\mathrm{rpm}) \\
& d_{p}=\text { diameter puli penggerak }(\mathrm{mm}) \\
& D_{p}=\text { diameter puli yang digerakan }(\mathrm{mm}) \\
& u=\text { perbandingan putaran }
\end{aligned}
$$

Diketahui:

$$
\begin{aligned}
& n_{1}=6000 \mathrm{rpm} \\
& n_{2}=2000 \mathrm{rpm} \\
& D_{p}=45 \mathrm{~mm} \\
& d_{p}=15 \mathrm{~mm}
\end{aligned}
$$


Maka perbandingan reduksi puli adalah:

$$
\begin{aligned}
& i=\frac{6000}{2000}=\frac{45}{15} \\
& i=3
\end{aligned}
$$

Maka perbandingan putaran puli adalah:

$$
\begin{aligned}
& u=\frac{1}{i} \\
& u=\frac{1}{3}
\end{aligned}
$$

\subsection{Perhitungan daya motor}

Poros merupakan merupakan komponen dari mesin parut kelapa yang memiliki peran penting dalam sistem trasmisi, poros ini berfungsi sebagai pemutar mata parut dan sebagai dudukan puli. Poros penggerak ini berbentuk silinder dengan ukuran diameter: $12 \mathrm{~mm}$, dan panjang: $180 \mathrm{~mm}$. Bahan poros pada mesin parut ini menggunakan baja S $45 \mathrm{C}$ dengan kekuatan tarik $58 \mathrm{~kg} / \mathrm{mm} 2$.

- Pertama kali harus menghitung daya yang diperlukan dari poros penggerak pisau ke puli: Jlka

$\mathrm{N}_{2}$ (putaran poros yang digerakkan) $=2000 \mathrm{RPM}$

Diameter mata pisau $=50 \mathrm{~mm}=0.05 \mathrm{~m}$

Beban Putaran dari Daging kelapa ke mata pisau $=5$ Newton maka:

Torsi $=\mathrm{F} \times \mathrm{d}$

Torsi $=5 \mathrm{~N} \times 0.05 \mathrm{~m}$

Torsi $=0.35 \mathrm{~N} . \mathrm{m}$

Daya poros yang diperlukan:

$$
\begin{gathered}
P=\frac{2 . \pi \cdot N \cdot T}{60} \\
P=\frac{2 \times 3.14 \times 2000 R P M \times 0.35 \mathrm{Nm}}{60} \\
P=\frac{4396}{60}(\mathrm{~kW})=73.3 \mathrm{~kW}
\end{gathered}
$$

Daya rencana poros:

$$
\begin{aligned}
& P_{d}=f_{c} \times P(\mathrm{~kW}) \\
& f_{c}=1.2(\text { faktor koreksi) } \\
& P_{d}=1.2 \times 73.3(\mathrm{~kW}) \\
& P_{d}=87.92 \mathrm{~kW}
\end{aligned}
$$


Power motor yang tersedia $=100 \mathrm{~kW}$, karena power motor masih lebih besar dari daya rencana poros maka power motor yang digunakan masih aman.

\section{KESIMPULAN DAN SARAN}

5.1 Kesimpulan

Hasil perancangan mesin parut kelapa adalah sebagai berikut:

1) Spesifikasi mesin, panjang: $365 \mathrm{~mm}$, lebar: $150 \mathrm{~mm}$, tinggi: $200 \mathrm{~mm}$.

2) Pengerak utama mesin menggunakan motor listik dengan kapasitas, input: 100 watt, 220 volt.

3) Sistem transmisi menggunakan sabuk (V-belt) dan puli, masing masing puli berdiameter 15 $\mathrm{mm}$ untuk puli motor dan $45 \mathrm{~mm}$ untuk puli poros pisau mata parut.

4) Kinerja mesin parut kelapa, untuk memarut satu buah kelapa yang berdiameter luar $130 \mathrm{~mm}$ dan tebal $12 \mathrm{~mm}$ diperlukan waktu 4 menit 4 detik, dan untuk memarut $1 \mathrm{~kg}$ kelapa diperlukan waktu 9,78 menit.

\subsection{Saran}

Proses penyempurnaan mesin masih diperlukan untuk meningkatkan kualitas mesin, usulan perbaikan rancangan mesin antara lain:

1) casing mesin sebaiknya menggunakan fiber atau besi plat steinlis, supaya tahan terhadap karat dan korosi.

2) Puli poros harusnya diperbesar lagi, agar meringankan motor untuk menggerakan pisau mata parut.

3) Pada saat pembersihan mesin setelah penggunaan sebaiknya menggunakan kuas kering, jangan menggunakan air.

\section{DAFTAR PUSTAKA}

- $\quad$ Sularso, Dasar Perencanaan dan Pemilihan Elemen Mesin, Jakarta : Pradya Paramita 1983.

- Dobrovolsky, V. "Machine Elements". Stolk, Jac. "Elemen Mesin", Erlangga, 1981.

- Maiseka Leu, M.A. Coward David, M.A. Marshall Craig. Alat Pemarut Kelapa dan Singkong. SERI BUKU PENGEMBANGAN MASYARAKAT DESA. Program Kerjasama DINSOSNAKERTRANSSIL. Edisi Ketiga. 2004 